\title{
FINAL RADIOCARBON INVESTIGATION OF PLATLAND TREE, THE BIGGEST AFRICAN BAOBAB
}

\author{
ADRIAN PATRUT' ${ }^{\mathrm{a}, *}$, STEPHAN WOODBORNE ${ }^{\mathrm{b}}$, \\ ROXANA T. PATRUT ${ }^{c}$, LASZLO RAKOSYc ${ }^{c}$ GRANT HALL', \\ ILEANA-ANDREEA RATIU ${ }^{a}$, KARL F. VON REDEN ${ }^{e}$
}

\begin{abstract}
The article discloses the main results of our new investigation of Platland tree, a.k.a. Sunland baobab, the largest known African baobab. Our recent research was motivated by the three successive splits of 2016 and 2017, which determined the collapse and demise of the stems that have built the main unit of the tree. According to our new findings concerning the architecture of large and old baobabs, we established that Platland tree has a double closed-ring shaped structure and consists of two units/rings that close two separate false cavities. The larger unit was composed of five fused stems, out of which four toppled and died, while the fifth stem is already broken. The smaller unit, which is still standing, consists of three fused stems. We also determined that the larger unit had an age of $800 \mathrm{yr}$, while the smaller unit is $1100 \mathrm{yr}$ old.
\end{abstract}

Keywords: AMS radiocarbon dating, Adansonia digitata, tropical trees, ringshaped structure, age determination, false cavity.

\section{INTRODUCTION}

The African baobab (Adansonia digitata L.), which has a natural distribution in mainland Africa, is the largest and best-known of the nine Adansonia species [1-3]. In 2005, we initiated a long-term research for

a Babeş-Bolyai University, Faculty of Chemistry and Chemical Engineering, 11 Arany Janos, RO-400028, Cluj-Napoca, Romania.

b iThemba Laboratories, Box 722 Somerset West, 7129, South Africa.

c Babeş-Bolyai University, Faculty of Biology and Geology, 44 Gheorghe Bilascu, RO-400015, Cluj-Napoca, Romania.

d Mammal Research Institute, University of Pretoria, 0001, South Africa.

e NOSAMS Facility, Dept. of Geology \& Geophysics, Woods Hole Oceanographic Institution, Woods Hole, MA 02543, U.S.A.

*Corresponding author: apatrut@gmail.com 
clarifying several controversial aspects concerning the architecture, growth and age of the African baobab. The research is mainly based on our methodology which consists of AMS radiocarbon dating of small wood samples collected from inner cavities, but also from deep incisions in the stems, fractured stems and from the exterior of large baobabs [4-8].

According to dating results, all large baobabs are multi-stemmed. Due to the special ability of baobabs to produce stems periodically during their life cycle, they develop architectures of increasing complexity. Therefore, we focused on the investigation of superlative individuals, i.e., very large and potentially old baobabs. We documented the open and closed ring-shaped structures, which are the most important architectures that enable African baobabs to reach old ages and large sizes. We also identified the presence of false cavities, which are large natural empty spaces between several fused stems disposed in a closed ring-shaped structure, which have never been filled with wood [9-13]. The oldest dated $A$. digitata specimens were found to have ages greater than $2000 \mathrm{yr}[14,15]$. Dated growth rings of several African baobab specimens act as a proxy climate archive and have been used for past climate reconstruction in southern Africa [16,17].

The Platland tree, a.k.a. Sunland baobab, is or was the biggest African baobab and also angiosperm, with a total wood volume of $501 \mathrm{~m}^{3}$ [8]. The Platland tree is probably the most promoted and visited African baobab. It is widely known especially due to the pub which was established inside its largest false cavity. Over the past years, we visited and investigated several times this superlative baobab. In our first radiocarbon investigation of a live African baobab, we determined the fire history of the Platland tree, by dating several new growths layers which covered the original old wood from its cavities. These new growth layers were triggered by successive fires inside the cavities [7]. In the second investigation, we determined the ages of the two units which build the Platland tree [8].

Here we present new results of the investigation of the Platland tree, mainly carried out after the successive splits of 2016 and 2017, which determined the collapse and death of its larger unit.

\section{RESULTS AND DISCUSSION}

The Platland tree and its area. The Platland tree is located on the private Sunland Mango Nursery of the former Platland farm, at $10 \mathrm{~km}$ from Modjadjiskloof and $25 \mathrm{~km}$ from Tzaanen, in the Limpopo Province, South Africa. Its GPS coordinates are $23^{\circ} 37.259^{\prime} \mathrm{S}, 030^{\circ} 11.888^{\prime} \mathrm{E}$ and the altitude is $717 \mathrm{~m}$. Mean annual rainfall in the area is $802 \mathrm{~mm}$ (Modjadjiskloof station). 

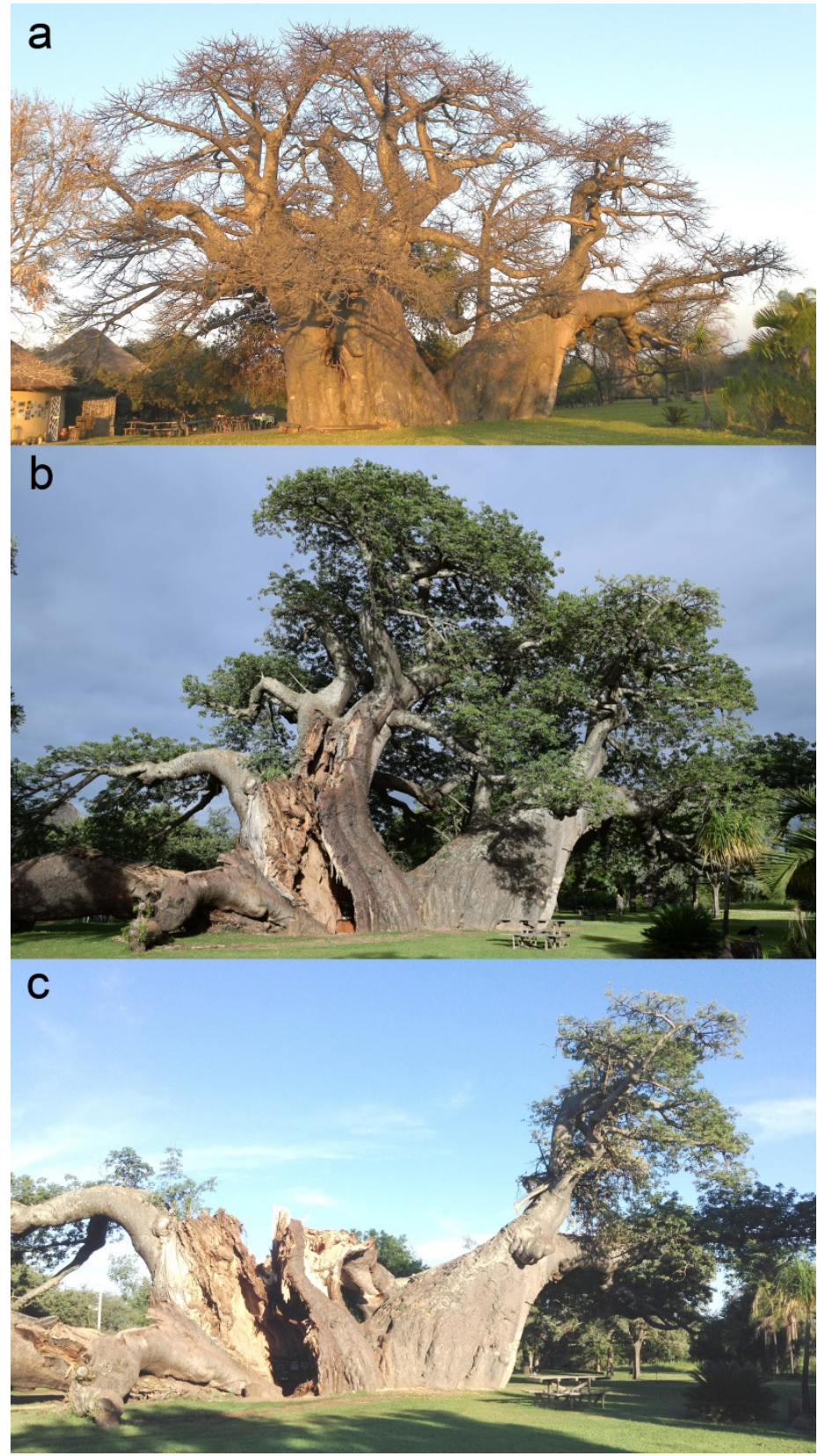

Figure 1. General view of the Platland tree taken from the east: (a) when it was still the largest African baobab; (b) after the second split of August 2016;

(c) after the third split of April 2017. 
The Platland tree consists of two units I and II, which are both multistemmed (Figure 1a). Its maximum height was $18.9 \mathrm{~m}$, the circumference at breast height (cbh; at $1.30 \mathrm{~m}$ above ground level) was $34.11 \mathrm{~m}$ and the basal surface of $67.9 \mathrm{~m}^{2}$ corresponded to a formal diametre of $9.30 \mathrm{~m}$. The overall wood volume was $501 \mathrm{~m}^{3}$, out of which $364 \mathrm{~m}^{3}$ for unit I and $137 \mathrm{~m}^{3}$ for unit II. The horizontal canopy dimensions are $37.7 \times 32.4 \mathrm{~m}$ [8].

The Platland tree has a double closed ring-shaped structure with two false cavities. The two units that build the tree correspond each to a closed ring. The two rings/units are connected by a fused section, which covers a shared cbh of $4.10 \mathrm{~m}$ and has a maximum height of $2.20 \mathrm{~m}$. The two false cavities are connected by a small opening.

The cavity inside the larger unit I has a maximum length of $4.60 \mathrm{~m}$, a width of $4.81 \mathrm{~m}$, a height of $4.88 \mathrm{~m}$ and a basal surface of $15.9 \mathrm{~m}^{2}$. The false cavity inside the smaller unit II has the linear dimensions of $1.67 \times 2.50 \times 2.47 \mathrm{~m}$ and a basal surface of $2.8 \mathrm{~m}^{2}$.

Unfortunately, the larger unit I of Platland tree split three times, in May 2016, August 2016 and April 2017. Four of its five stems toppled and died. The fifth stem which is broken will also collapse soon (Figure 1b and 1c). The stems of the larger unit I were partially rotten. It is still uncertain whether the smaller unit II, composed of three stems, which was hit during the third split, will survive or not.

Wood samples. Five wood samples (labelled 11-15) were collected from two fallen stems of unit I. Other two samples (labelled 21 and 22) were collected from the walls of the false cavity inside unit II.

A number of seven small pieces/segments, of the length of $0.001 \mathrm{~m}$ each, were extracted from the samples 11-15 and from the deepest ends of samples 21 and 22.

AMS results and calibrated ages. Radiocarbon dates of the seven segments are listed in Table 1. Radiocarbon dates and errors were rounded to the nearest year. The radiocarbon dates are expressed in ${ }^{14} \mathrm{C}$ yr BP (radiocarbon years before present, i.e., before the reference year AD 1950).

Calibrated (cal) ages, expressed in calendar years, are also displayed in Table 1. The 1- $\sigma$ probability distribution was selected to derive calibrated age ranges. For four sample segments the 1- $\sigma$ distribution is consistent with only one range of calendar years. For the other three sample segments, the $1-\sigma$ distribution is consistent with two or three ranges of calendar years. For these three segments, the confidence interval of one range is considerably greater than that of the other(s); therefore, it was selected as the cal $A D$ range of the segment for the purpose of this discussion. For obtaining single calendar age values of sample segments, we derived a mean age of each 
segment from the selected range (marked in bold). Calendar ages of segments represent the difference between AD 2017 and the mean value of the selected range, with the corresponding error. Calendar ages and errors were rounded to the nearest $5 \mathrm{yr}$.

Table 1. AMS Radiocarbon dating results and calibrated calendar ages of samples/segments collected from the Platland tree.

\begin{tabular}{|c|c|c|c|c|}
\hline $\begin{array}{c}\text { Sample } \\
\text { (Segment) }\end{array}$ & $\begin{array}{l}\text { Depth }^{1} \\
{\left[\text { height }^{2}\right]} \\
\left(10^{-2} \mathrm{~m}\right)\end{array}$ & \begin{tabular}{|c|} 
Radiocarbon date \\
[error] \\
$\left({ }^{14} \mathrm{C}\right.$ yr BP $)$
\end{tabular} & $\begin{array}{c}\text { Cal AD range } \\
1-\sigma \\
\text { [confidence interval] }\end{array}$ & $\begin{array}{c}\text { Sample age } \\
\text { [error] } \\
\text { (cal yr) }\end{array}$ \\
\hline 11 & - & $665[ \pm 23]$ & $\begin{array}{l}\mathbf{1 3 1 4}-1358[54.4 \%] \\
1380-1391[13.8 \%]\end{array}$ & $680[ \pm 20]$ \\
\hline 12 & - & $765[ \pm 18]$ & $1276-1294[68.2 \%]$ & $730[ \pm 10]$ \\
\hline 13 & - & $546[ \pm 19]$ & $1413-1434[68.2 \%]$ & $595[ \pm 10]$ \\
\hline 14 & - & $728[ \pm 16]$ & $\begin{array}{l}\mathbf{1 2 8 2}-1302[\mathbf{5 2 . 3} \%] \\
1365-1375[15.9 \%]\end{array}$ & $725[ \pm 10]$ \\
\hline 15 & - & $785[ \pm 18]$ & $1266-1288[68.2 \%]$ & $740[ \pm 10]$ \\
\hline 21 & $\begin{array}{c}35 \\
{[135]}\end{array}$ & $914[ \pm 25]$ & $1160-1208[68.2 \%]$ & $835[ \pm 25]$ \\
\hline 22 & $\begin{array}{c}42 \\
{[160]}\end{array}$ & $978[ \pm 14]$ & $\begin{array}{c}\mathbf{1 0 4 6 - 1 0 8 9}[\mathbf{4 1 . 0 \%}] \\
1109-1120[7.9 \%] \\
1130-1151[19.3 \%]\end{array}$ & $950[ \pm 20]$ \\
\hline
\end{tabular}

${ }^{1}$ Depth in the wood from the sampling point.

${ }^{2}$ Height above ground level.

Dating results of samples (segments). The five sample segments 11-15 originate from relatively central positions of two fallen and broken stems of unit I, namely from different heights $(4.3-10.5 \mathrm{~m})$, i.e., distances from their original base. Their radiocarbon dates between $546 \pm 19$ and $785 \pm 18 \mathrm{BP}$ correspond to calibrated ages of $595 \pm 10$ and $740 \pm 10$ calendar yr. Other samples collected from areas around the circumference of the two fallen stems, in direction of the cavity and in the opposite direction toward the outer part/exterior were also dated and found to be greater than Modern (> Modern). In such cases, the dated wood is very young, being formed after $A D$ 1950. The two sample segments 21 and 22, which represent the deepest end of the two samples collected from the walls of the false cavity inside unit II, had radiocarbon dates of $914 \pm 25$ and $978 \pm 14$ BP. These values correspond to calibrated ages of $835 \pm 25$ and $950 \pm 20$ calendar yr.

Architecture of the Platland tree. The Platland tree was composed of two interconnected units, which were both multi-stemmed. Each unit, which has a false cavity inside, exhibits a closed ring-shaped structure. Thus, the 
Platland tree has a double closed ring-shaped structure with two distinct false cavities that communicate via a small opening. The largest unit I was composed of five perfectly fused stems, that collapsed one after another during the three successive splits. The still standing smaller unit II consists of three fused stems.

Ages of the two units of Platland tree. The ages of the five samples 11-15 extracted from two toppled and broken stems of unit I, that were partially rotten, were between 595 and $740 \mathrm{yr}$. The oldest samples originate from areas close to the presumptive pith (at the respective height) for stems which belong to a closed-ring shaped structure. We consider that the age of the oldest part of unit I must have been close to $800 \mathrm{yr}$.

The oldest dated sample segment corresponds to the deepest end of sample 22, which was collected from the inner cavity walls inside unit II. This segment that correspond to a depth of $0.42 \mathrm{~m}$ in the wood from the sampling point, was $950 \mathrm{yr}$ old. By considering that the width of the cavity walls in this area is $1.20 \mathrm{~m}$ and also the age sequences of stems which belong to a ringshaped structure, we estimate that the age of unit II is around $1100 \mathrm{yr}$.

These ages of the two units of Platland tree are very close to the age values proposed by us in a previous research, in which we also discussed a possible scenario for explaining why the smaller unit II is considerably older than the larger unit I [8].

\section{CONCLUSIONS}

The research presents the results of the final investigation of the largest known African baobab, namely the Platland tree, a.k.a. Sunland baobab, located in the Limpopo province, South Africa. This new research, which was mainly based on AMS (accelerator mass spectrometry) radiocarbon dating, aimed to establish the true architecture and age of the baobab. We determined that the Platland tree has a double closed ring-shaped structure and consists of two units/rings with two distinct false cavities inside.

The larger unit/ring was composed of five fused stems, while the smaller unit/ring consists of three fused stems. In 2016 and 2017, the larger unit split three times, so that four stems toppled and died. According to the new dating results, the larger unit was $800 \mathrm{yr}$ old, while the still standing smaller unit has an age of $1100 \mathrm{yr}$.

The death of the majority of the oldest and largest African baobabs, which were all located in southern Africa, over the past years, is an event of an unprecedented gravity. The fact that these demises were not caused by an epidemic suggests that they were engendered by significant modifications of the climate conditions, which affect especially southern Africa. The devastating drought over the past years in southern Africa was determined mainly by the 
intensification of El Niño, which warms the waters in the equatorial Pacific and can lead to unusually heavy rains in some parts of the world and drought elsewhere. The Platland tree might be the latest victim of these climate modifications.

\section{EXPERIMENTAL SECTION}

Sample collection. The five wood samples 11-15, which originate from unit I, were extracted with a sharp instrument from central areas of two fallen and broken stems, which were partially decayed. The other two samples 21 and 22 were collected by using a Haglöf $\mathrm{CH} 800$ increment borer $(0.80 \mathrm{~m}$ long, $0.0054 \mathrm{~m}$ inner diametre) from the walls of the cavity inside unit II. A number of seven tiny pieces/segments of the length of $0.001 \mathrm{~m}$ were extracted from each wood sample. The segments were processed and investigated by AMS radiocarbon dating.

Sample preparation. The standard acid-base-acid pretreatment method was used for removing soluble and mobile organic components. The pretreated samples were combusted to $\mathrm{CO}_{2}$ by using the closed tube combustion method [18]. Then, $\mathrm{CO}_{2}$ was reduced to graphite on iron catalyst, under hydrogen atmosphere [19]. Finally, the resulting graphite samples were analysed by AMS.

AMS measurements. AMS radiocarbon measurements were performed at the NOSAMS Facility of the Woods Hole Oceanographic Institution (Woods Hole, MA, U.S.A.) by using the Pelletron $®$ Tandem 500 kV AMS system. The obtained fraction modern values, corrected for isotope fractionation with the normalized $\delta^{13} \mathrm{C}$ value of $-25 \%$, were ultimately converted to a radiocarbon date.

Calibration. Radiocarbon dates were converted into calendar ages with OxCal v4.2 for Windows [20], using the SHCal13 atmospheric set [21].

\section{ACKNOWLEDGMENTS}

Authors thank Heather and Doug van Heerden, the owners of Sunland Nursery, for granting permission and providing support for the investigation and sampling of the Platland baobab. The research was funded by the Romanian Ministry of Scientific Research CNCS-UEFISCDI under grant PN-II-ID-PCE-2013-76. 


\section{REFERENCES}

1. G.E. Wickens, P. Lowe, "The Baobabs: Pachycauls of Africa, Madagascar and Australia", Springer, Dordrecht, 2008.

2. D.A. Baum, Annals of the Missouri Botanical Garden, 1995, 82, 440-471.

3. J.D. Pettigrew, L.K. Bell, A. Bhagwandin, E. Grinan, N. Jillani, J. Meyer, E. Wabuyele, C.E. Vickers, Taxon, 2013, 61, 1240-1250.

4. A. Patrut, K.F. von Reden, D.A. Lowy, A.H. Alberts, J.W. Pohlman, R. Wittmann, D. Gerlach, L. Xu, C. S. Mitchell, Tree Physiology, 2007, 27, 1569-1574.

5. A. Patrut, K.F. von Reden, D.A. Lowy, D.H. Mayne, K. E. Elder, M.L. Roberts, A.P. McNichol, Nuclear Instruments and Methods in Physics Research Section B, 2010, 268, 910-913, doi: 10.1016/j.nimb.2009.10.062.

6. A. Patrut, D.H. Mayne, K.F. von Reden, D.A. Lowy, S. Venter, A.P. McNichol, M.L. Roberts, D. Margineanu, Radiocarbon, 2010, 52, 727-734.

7. A. Patrut, D.H. Mayne, K.F. von Reden, D.A. Lowy, R. Van Pelt, A.P. McNichol, M.L. Roberts, D. Margineanu, Radiocarbon, 2010, 52, 717-726.

8. A. Patrut, K.F. von Reden, R. Van Pelt, D.H. Mayne, D.A. Lowy, D. Margineanu, Annals of Forest Science, 2011, 68, 993-1003.

9. A. Patrut, S. Woodborne, K.F. von Reden, G. Hall, M. Hofmeyr, D. Lowy, R.T. Patrut, PLoS ONE, 2015, 10(1), e0117193, doi: 10.1371/journal.pone.0117193.

10. A. Patrut, S. Woodborne, R.T. Patrut, G. Hall, L. Rakosy, K.F. von Reden, D. Lowy, D. Margineanu, Studia UBB Chemia, 2015, LX, 4, 7-20.

11. A. Patrut, L. Rakosy, R.T. Patrut, I.A. Ratiu, E. Forizs, D.A. Lowy, D. Margineanu, K.F. von Reden, Studia UBB Chemia, 2016, LXI, 4, 7-20.

12. A. Patrut, R.T. Patrut, L. Rakosy, J. Bodis, D.A. Lowy, E. Forizs, K.F. von Reden, Studia UBB Chemia, 2016, LXI, 4, 21-30.

13. A. Patrut, S. Garnaud, O. Ka, R.T. Patrut, T. Diagne, D.A. Lowy, E. Foris, J. Bodis, K.F. von Reden, Studia UBB Chemia, 2017, LXII, 1, 111-120, doi:10.24193/subbchem.2017.1.09.

14. A. Patrut, K.F. von Reden, D.H. Mayne, D.A. Lowy, R.T. Patrut, Nuclear Instruments and Methods in Physics Research Section B, 2013, 294, 622-626, doi: 10.1016/j.nimb.2012.04.025.

15. A. Patrut, S. Woodborne, K.F. von Reden, G. Hall, R.T. Patrut, L. Rakosy, P. Danthu, J-M. Leong Pock-Tsy, D.A. Lowy, D. Margineanu, Radiocarbon, 2017, 59(2), 435-448, doi: 10.1017/RDC.2016.92.

16. S. Woodborne, G. Hall, I. Robertson, A. Patrut, M. Rouault, N.J. Loader, M. Hofmeyr, PLOS ONE, 2015, 10(5), e0124202, doi: 10.1371/journal.pone.0124202.

17. S. Woodborne, P. Gandiwa, G. Hall, A. Patrut, J. Finch, PLoS ONE, 2016, 11(7), e015936, doi: 10.1371/journal.pone.0159361.

18. Z. Sofer, Analytical Chemistry, 1980, 52, 1389-1391.

19. J.S. Vogel, J.R. Southon, D.E. Nelson, T. A. Brown, Nuclear Instruments and Methods in Physics Research Section B, 1984, 5, 289-293.

20. C. Bronk Ramsey, Radiocarbon, 2009, 51, 337-360.

21. A.G. Hogg, Q. Hua, P.G. Blackwell, M. Niu, C.E. Buck, T.P. Guilderson, T.J. Heaton, J.G. Palmer, P.J. Reimer, R.W. Reimer, C.S.M. Turney, R.H. Zimmerman, Radiocarbon, 2013, 55, 1889-1903. 